\title{
Hepatocyte-Specific Expression of Human Lysosome Acid Lipase Corrects Liver Inflammation and Tumor Metastasis in $\mathrm{Ial}^{-/-}$Mice
}

\author{
Hong Du, ${ }^{* \dagger}$ Ting Zhao, ${ }^{*}$ Xinchun Ding, ${ }^{*}$ and Cong Yan ${ }^{* \dagger \ddagger}$
}

From the Department of Pathology and Laboratory Medicine, $*$ the IU Simon Cancer Center, ${ }^{\dagger}$ and The Center for Immunobiology, ${ }^{\ddagger}$ Indiana University School of Medicine, Indianapolis, Indiana

\author{
Accepted for publication \\ May 18, 2015. \\ Address correspondence to \\ Hong Du, Ph.D., or Cong Yan, \\ Ph.D., Department of Pathology \\ and Laboratory Medicine, \\ Indiana University School of \\ Medicine, 975 W Walnut St., \\ IB424E, Indianapolis, \\ IN 46202. E-mail: hongdu@ \\ iupui.edu or coyan@iupui.edu.
}

\begin{abstract}
The liver is a major organ for lipid synthesis and metabolism. Deficiency of lysosomal acid lipase (LAL; official name Lipa, encoded by Lipa) in mice $\left(\right.$ lal $\left.^{-/-}\right)$results in enlarged liver size due to neutral lipid storage in hepatocytes and Kupffer cells. To test the functional role of LAL in hepatocyte, hepatocytespecific expression of human $\mathrm{LAL}(\mathrm{hLAL})$ in $\mathrm{lal}^{-/-}$mice was established by cross-breeding of liveractivated promoter (LAP)-driven tTA transgene and (tet 0$)_{7}-\mathrm{CMV}$-hLAL transgene with lal $^{-/-}$ knockout (KO) (LAP-Tg/KO) triple mice. Hepatocyte-specific expression of hLAL in LAP-Tg/KO triple mice reduced the liver size to the normal level by decreasing lipid storage in both hepatocytes and Kupffer cells. hLAL expression reduced tumor-promoting myeloid-derived suppressive cells in the liver of lal $^{-/-}$mice. As a result, B16 melanoma metastasis to the liver was almost completely blocked. Expression and secretion of multiple tumor-promoting cytokines or chemokines in the liver were also significantly reduced. Because $\mathrm{hLAL}$ is a secretory protein, $\mathrm{lal}^{-/-}$phenotypes in other compartments (eg, blood, spleen, and lung) also ameliorated, including systemic reduction of myeloid-derived suppressive cells, an increase in $\mathrm{CD}^{+}$and $\mathrm{CD}^{+}{ }^{+} \mathrm{T}$ and $\mathrm{B}$ lymphocytes, and reduced $\mathrm{B} 16$ melanoma metastasis in the lung. These results support a concept that LAL in hepatocytes is a critical metabolic enzyme in controlling neutral lipid metabolism, liver homeostasis, immune response, and tumor metastasis. (Am J Pathol 2015, 185: 2379-2389; http://dx.doi.org/10.1016/j.ajpath.2015.05.021)
\end{abstract}

Lysosomal acid lipase (LAL) (official name LIPA, encoded by LIPA) hydrolyzes cholesteryl esters (CEs) and triglycerides (TGs) in lysosomes. Mutation in LIPA results in Wolman disease (WD) as early infantile onset and CE storage disease (CESD) as late onset. ${ }^{1-3}$ Infants with WD have massive accumulations of CEs and TGs in the lysosomes of hepatocytes and Kupffer cells, as well as in macrophages throughout the viscera, which lead to liver failure, severe hepatosplenomegaly, steatorrhea, pulmonary fibrosis, and adrenal calcification. ${ }^{2}$ Patients with CESD have the major symptom of hepatomegaly with increased hepatic levels of CEs, which reveals microvesicular steatosis leading to fibrosis and cirrhosis in the liver and increases atherosclerosis and premature demise. ${ }^{4-6}$

An LAL knockout (KO) mouse model $\left(\right.$ lal $\left.^{-/-}\right)$resembles human CESD, and its biochemical and histopathologic phenotypes mimic human WD. ${ }^{7,8}$ The $l a l^{-1-}$ mice are normal appearing at birth but develop liver enlargement by 1.5 months and have a grossly enlarged abdomen with hepatosplenomegaly and lymph node enlargement. ${ }^{7,8}$ One interesting character of $l a l^{-1-}$ mice is a systemic expansion (including the liver) of $\mathrm{CD}_{11} \mathrm{~b}^{+} \mathrm{Ly}_{6 \mathrm{G}}{ }^{+}$cells, which are similar to myeloid-derived suppressive cells (MDSCs) in tumorigenesis. ${ }^{9-11}$ MDSCs influence the tissue microenvironment and contribute to local pathogenesis. ${ }^{7-13}$ In humans, increased $\mathrm{CD}_{14}{ }^{+} \mathrm{CD} 16^{+}$and $\mathrm{CD} 14^{+} \mathrm{CD} 33^{+}$cells (human subsets of MDSCs) have been linked to heterozygote carriers of LAL mutations. ${ }^{14}$ Hepatocellular carcinoma has been linked to chronic inflammation with elevated MDSC counts. $^{15-17}$

Supported by NIH grants HL087001 (H.D.) and CA138759 and CA152099 (C.Y.).

Disclosures: None declared. 
To better understand the physiologic role of LAL in hepatocytes and the link to clinical application, hepatocytespecific expression of human LAL (hLAL) in $l a l^{-1-}$ mice was achieved by crossbreeding a liver-activated promoter (LAP)-driven tTA transgene (LAP-tTA) and a (tetO) $)_{7^{-}}$ CMV-hLAL transgene (Tet off system) into $\mathrm{lal}^{-/-}$mice (LAP-Tg/KO mice). Histologic and tissue lipid analyses revealed a correction of lipid storage in the liver, spleen, and small intestine in doxycycline-untreated LAP-Tg/KO mice (hLAL induction turns on) compared with doxycyclinetreated $\mathrm{LAP}-\mathrm{Tg} / \mathrm{KO}$ mice (hLAL induction turns off). Flow cytometry analyses revealed reduced tumor-promoting MDSCs in the liver of LAP-Tg/KO mice. Furthermore, hLAL overexpression in hepatocytes greatly reduced metastasis of B16 melanoma into the liver. These pathogenic phenotypes were associated with a decrease of inflammatory cytokine and chemokine levels. Together, these results indicate that hepatic LAL plays an important role in lipid metabolism, cytokine production, MDSCs influx into organs, and tumor metastasis in the liver.

\section{Materials and Methods}

\section{Animal Care and Cell Lines}

LAP-tTA/(TetO) $)_{7}$-CMV-hLAL; $l a l^{-/}{ }^{-}$(LAP-Tg/KO) triple mice of the FVB/N background was established by crossbreeding of LAP-tTA transgenic mice (Jackson's Laboratory, Bar Harbor, ME) with a previously generated $(\text { tetO })_{7}$-CMV-hLAL transgenic mice ${ }^{18}$ into $l a l^{-/-}$mice. This triple transgenic mouse model is hepatocyte-specific Tet-off expression of wild-type hLAL in lal $^{-/-}$mice under the control of the LAP. All scientific protocols that involved the use of animals have been approved by the Institutional Animal Care and Use Committee of Indiana University School of Medicine and followed guidelines established by the Panel on Euthanasia of the American Veterinary Medical Association. Animals were housed in a secured animal facility at Indiana University School of Medicine. The murine B16 melanoma cell line (ATCC, Manassas, VA) was cultured in Dulbecco's modified Eagle's medium supplemented with $10 \%$ fetal bovine serum (Gibco, Grand Island, NY).

\section{Characterization of Tissue Expression of the hLAL Transgene by RT-PCR}

Total RNAs from the liver, lung, spleen, and bone marrow cells of wild-type, $\mathrm{lal}^{-/-}$, and $\mathrm{LAP}-\mathrm{Tg} / \mathrm{KO}$ triple mice or hepatocytes and $\mathrm{Ly} 6 \mathrm{G}^{+}$cells isolated from the liver were purified using a total RNA purification kit (Qiagen, Valencia, $\mathrm{CA})$. $\mathrm{Ly}_{6} \mathrm{G}^{+}$cells from the liver were isolated by incubation with biotin-labeled anti-Ly6G ${ }^{+}$antibody after liver perfusion, followed by incubation with anti-biotin immunemagnetic microbeads and magnetic-activated cell sorting technique according to the manufacturer's instruction

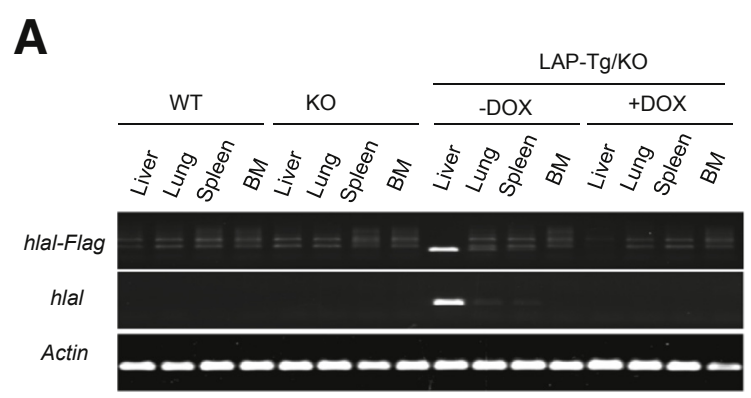

B

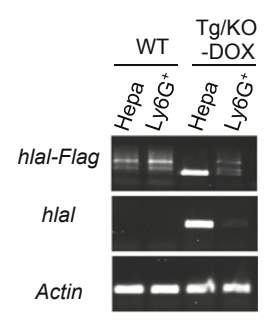

C

\begin{tabular}{|c|c|c|c|}
\hline \multirow[b]{2}{*}{ WT } & \multirow[b]{2}{*}{ KO } & \multicolumn{2}{|c|}{ LAP-Tg/KO } \\
\hline & & -DOX & + DOX \\
\hline
\end{tabular}

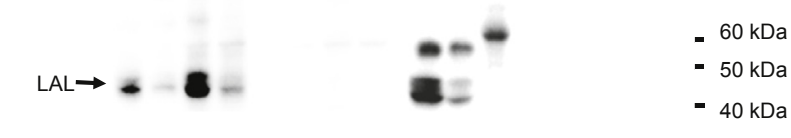

D

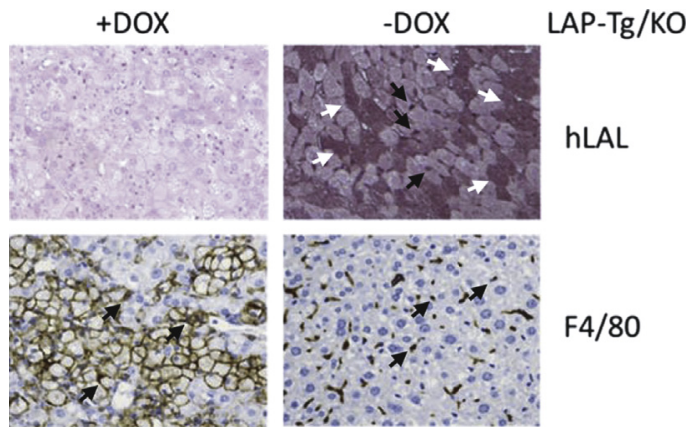

Figure 1 Human LAL (hLAL) expression in wild-type (WT), lal ${ }^{-/-}(\mathrm{K} 0)$, and liver-activated promoter (LAP)-driven tTA transgene and (tet0) ${ }_{7}$-CMVhLAL transgene with lal $^{-/-}(\mathrm{LAP}-\mathrm{Tg} / \mathrm{KO})$ triple mice. A: RT-PCR for hLAL mRNA expression in the liver, lung, spleen, and bone marrow (BM) of WT, KO, and LAP- $\mathrm{Tg} / \mathrm{KO}$ triple mice treated with or without doxycycline (DOX). The housekeeping gene $\beta$-actin was used as an internal control. B: RT-PCR for hLAL mRNA expression in isolated primary hepatocytes and $\mathrm{Ly}_{6 \mathrm{G}}{ }^{+}$cells from WT and LAP-Tg/KO triple mouse liver without DOX. The housekeeping gene $\beta$-actin was used as an internal control. C: Western blot analysis of LAL protein in the liver, lung, spleen, and bone marrow of WT, lal ${ }^{-/}(\mathrm{KO})$, and LAP- $\mathrm{Tg} / \mathrm{KO}$ triple mice, treated or untreated with DOX. D: Immunohistochemical staining of $h L A L$ and $F 4 / 80$ in the livers of DOX-treated (+DOX) or DOX-untreated (-DOX) LAP-Tg/K0 triple mice. White arrows indicate representative hepatocytes that express $\mathrm{hLAL}$. Black arrows indicate the $\mathrm{F} 4 / 80^{+}$Kupffer cells that are also positive for hLAL. Without hLAL expression, there is accumulation of enlarged F4/80-positive storage cells in DOX-treated LAP- $\mathrm{Tg} / \mathrm{KO}$ triple mice. Original magnification: $\times 200$. Hepa, hepatocyte, $\mathrm{Ly}_{6 \mathrm{G}}{ }^{+}, \mathrm{Ly}_{6 \mathrm{G}}{ }^{+}$cells from the liver (B). 
A
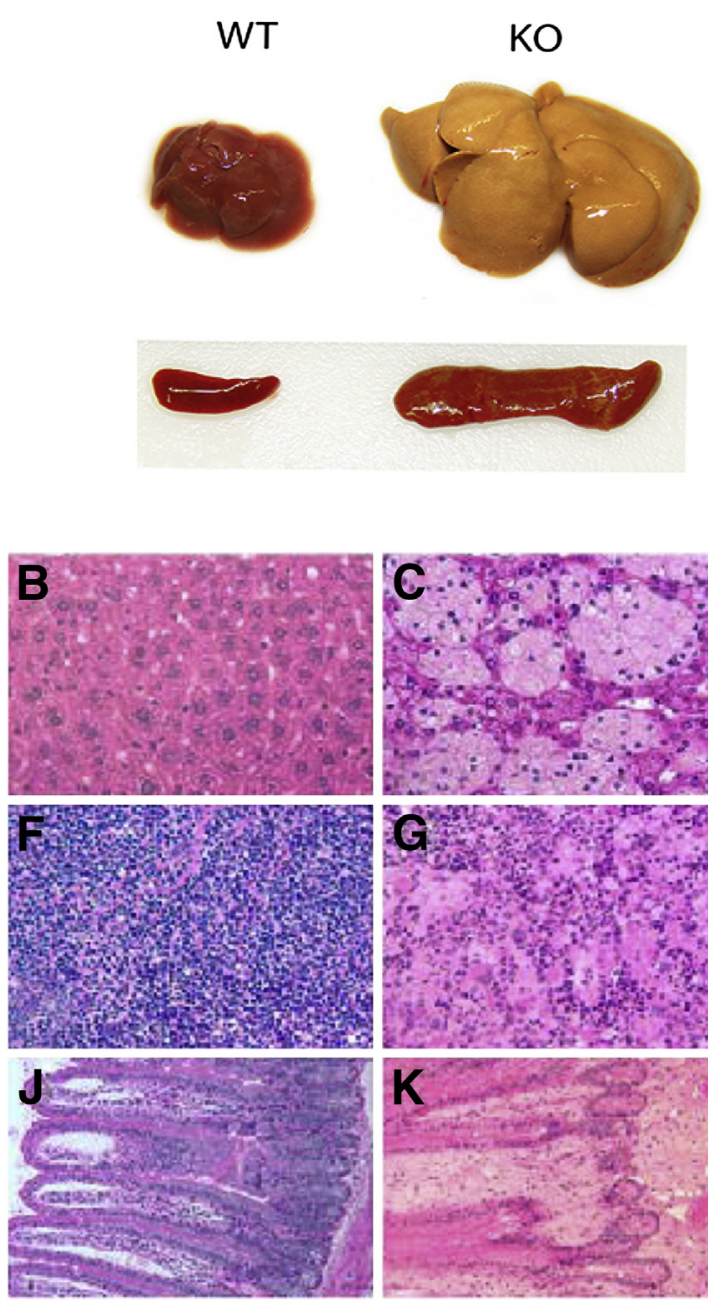

WT
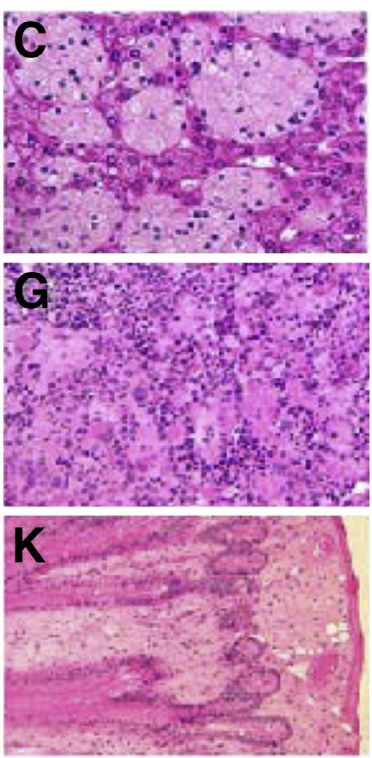

$\mathrm{KO}$
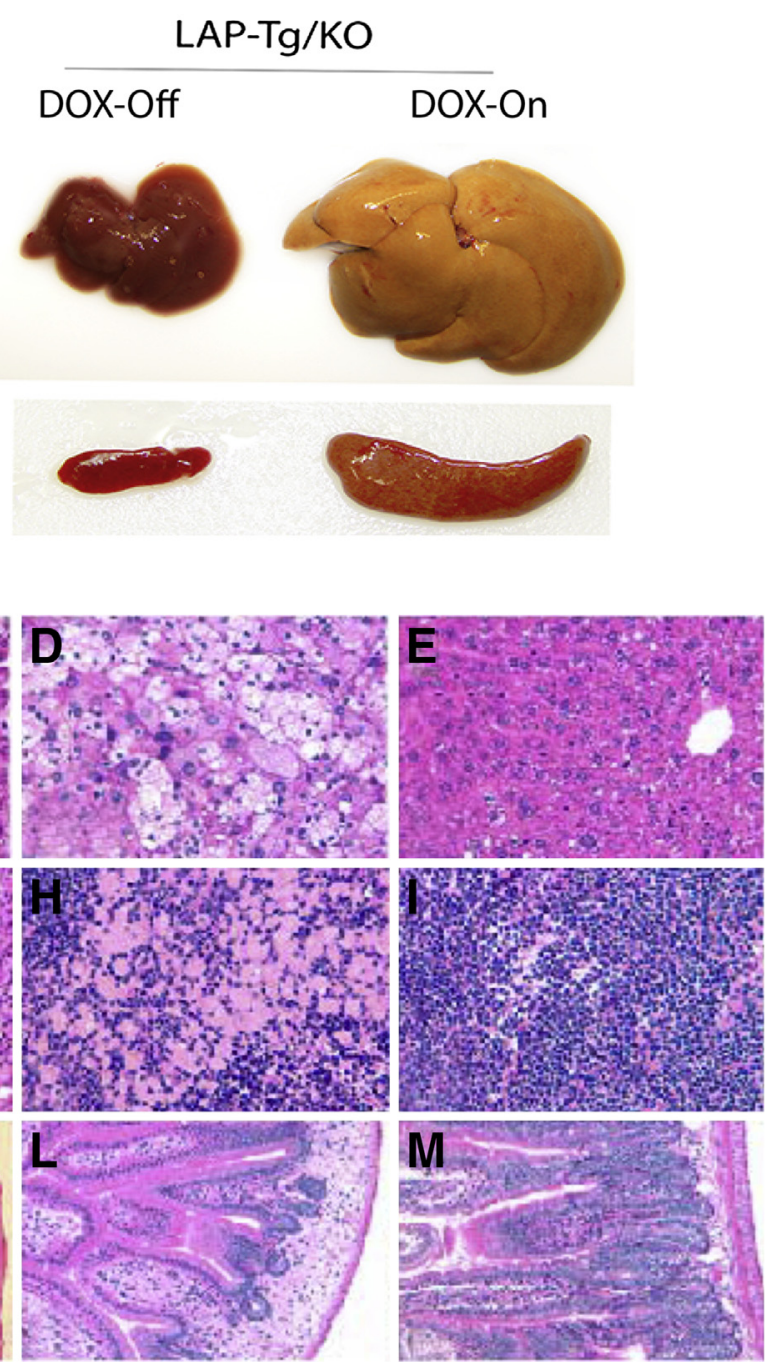

DOX-On

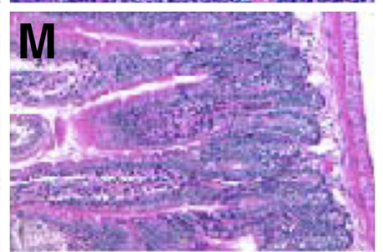

DOX-Off

\section{LAP-Tg/KO}

Figure 2 Hepatic expression of hLAL in liver-activated promoter (LAP)-driven tTA transgene and (tet0) $)_{7}$-CMV-hLAL transgene with lal ${ }^{-/-}$(LAP-Tg/K0) mice corrects abnormality in the liver, spleen, and small intestine. A: Gross view of the liver and spleen of $l a l^{+/+}$[wild-type (WT)], lal ${ }^{-/-}$(KO), and doxycycline-untreated (DOX-Off) and doxycycline-treated (DOX-On) LAP- $\mathrm{Tg} / \mathrm{KO}$ mice. B-M: Hematoxylin and eosin staining of the liver, spleen, and small intestine paraffin sections from WT (B, F, and J), lal ${ }^{-/-}(\mathrm{KO})(\mathbf{C}, \mathbf{G}$, and $\mathbf{K})$, DOX-ON (D, H, and L), and DOX-OFF (E, I, and M) LAP-Tg/KO mice. Original magnification: $\times 200(B-M)$.

(Miltenyi Biotech, Auburn, CA). cDNA was generated by a reverse transcription kit (Invitrogen, Grand Island, NY) from isolated total RNA. PCR amplification was used two different sets of primers for verification of hLAL expression. The first pair of primers cover different exons (exons 8 and 9) unique to the hLAL gene (forward primer, 5'-AGCCAGGCTGTTAAATTCCAAA-3'; reverse primer, $5^{\prime}$-GAATGCTCTCATGGAACACCAA- $3^{\prime}$ ). The second pair of primers cover an exon (exon 9) that is unique to the hLAL gene and the Flag epitope coding sequence that is at the $3^{\prime}$ end of hLAL cDNA in the (tetO) $)_{7}-\mathrm{CMV}$-hLAL vector, which is unique to the hLAL-Flag combination (forward primer, 5'-TGCAGTCTGGAGCGGGG-3'; reverse primer,
$5^{\prime}$-TGTCATCGTCGTCCTTGTAGTCC-3'). The housekeeping gene $\beta$-actin (forward primer, $5^{\prime}$-ACCGTGAAAAGATGACCCAGAT-3'; reverse primer, 5'-GCCTGGATGGCTACGTACATG- $3^{\prime}$ ) was used as an internal control. PCR were performed on Mastercycler (Eppendorf, Hamburg, Germany).

\section{Western Blot Analysis of hLAL Protein Expression}

Protein samples from the liver, lung, spleen, and bone marrow cells of wild-type, $\mathrm{lal}^{-/-}$, and LAP-Tg/KO mice were prepared in the Cell Lytic M mammalian cell lysis/extraction buffer (Sigma-Aldrich, St Louis, MO) according to the manufacturer's 

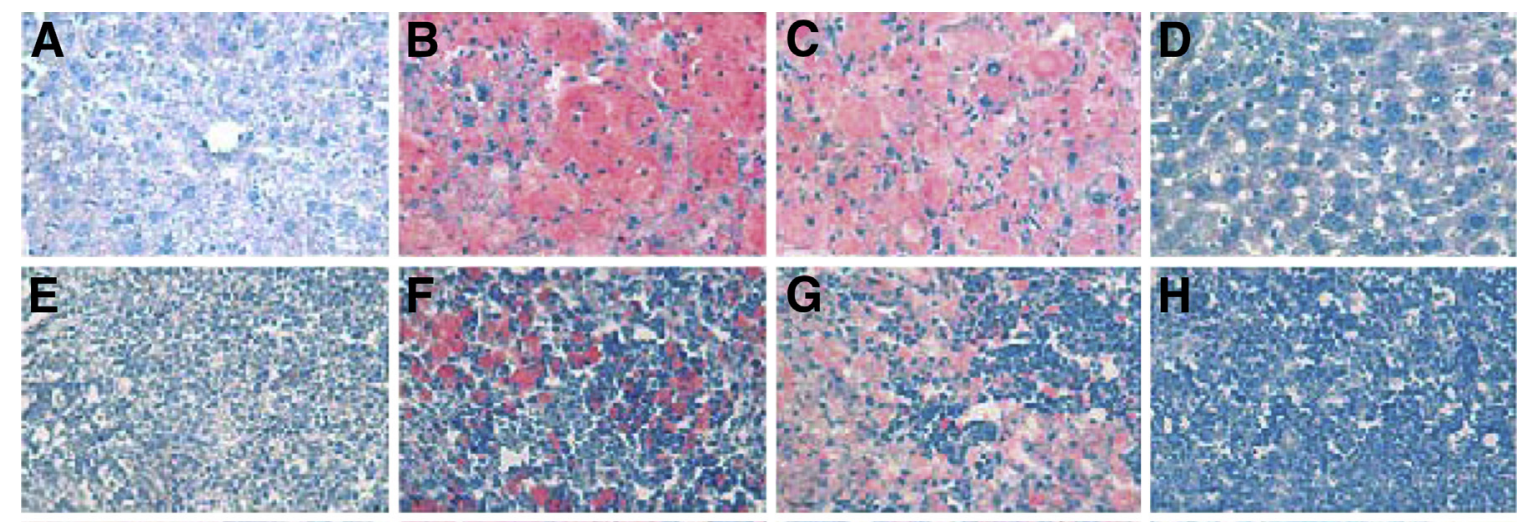

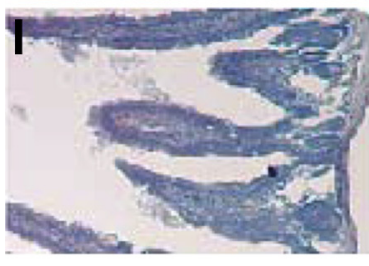

WT

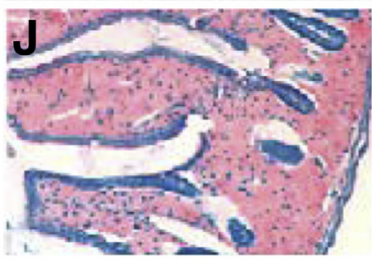

$\mathrm{KO}$

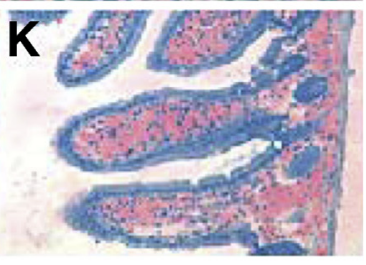

DOX-On

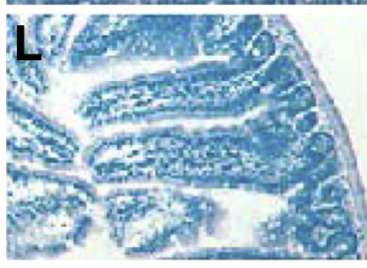

DOX-Off

\section{$\mathrm{LAP}-\mathrm{Tg} / \mathrm{KO}$}

Figure 3 Hepatic expression of human lysosomal acid lipase (hLAL) in liver-activated promoter (LAP) - driven tTA transgene and (tet0) $)_{7}$-CMV-hLAL transgene with $\mathrm{lal}^{-1-}(\mathrm{LAP}-\mathrm{Tg} / \mathrm{KO})$ mice corrects neutral lipid storage in the liver, spleen, and small intestine. 0il Red-0 staining of liver, spleen, and small intestine frozen sections from wild-type (WT) (A, E, and I), lal ${ }^{-/-}(\mathrm{KO})(\mathbf{B}, \mathbf{F}$, and J), doxycycline-treated (DOX-On) (C, G, and K), and doxycycline-untreated (DOX-Off) (D, H, and L) $\mathrm{LAP}-\mathrm{Tg} / \mathrm{KO}$ mice. Original magnification: $\times 200(\mathbf{A}-\mathbf{L})$.

instruction. Protein samples were fractionated on a Novex $4 \%$ to $20 \%$ Tris-Glycine Mini Gel (Invitrogen). After protein transferred to the polyvinylidene difluoride membrane (BioRad, Hercules, CA), the membrane was blotted with 5\% nonfat dry milk in $1 \times$ phosphate-buffered saline with $0.05 \%$ Tween 80 and incubated with rabbit anti-LAL and anti-actin primary antibodies (Cell Signaling, Danvers, MA). After incubation with the secondary antibody that conjugated with horseradish peroxidase, proteins were visualized with chemiluminescent substrate under the ChemiDocTM MP Image System (Thermo Fisher Scientific, Waltham, MA).

\section{Tissue Lipid Extraction and Determination of CE and TG Concentrations}

Total tissue lipids were extracted from the liver and small intestine by the Folch method. ${ }^{19}$ Concentrations of CEs and TGs were determined as previously described. ${ }^{8,20}$

\section{Oil Red-0 Staining}

Frozen tissue sections were prepared from the liver and intestine after a standard cryostat procedure. Tissue section slides were stained with Oil Red-O solution $(0.5 \%$ in propylene glycol) in a $60^{\circ} \mathrm{C}$ oven for 10 minutes and placed in $85 \%$ propylene glycol for 1 minute; slides were counterstained in hematoxylin.

\section{IHC Staining}

Tissues from the liver, intestine, and lung were collected after mice were anesthetized. All tissues were washed with phosphate-buffered saline and dehydrated by a series of increasing ethanol concentrations, followed by paraffin embedding. Sections were stained with anti-Ki67 antibody, antiLAL antibody, and anti-F4/80 antibody by the histologic core.

\section{Flow Cytometry Analysis}

Single-cell suspensions from the bone marrow, spleen, blood, liver, and lung were prepared and analyzed as previously described. ${ }^{9,10,21}$ Approximately $1 \times 10^{6}$ cells from various organs were blocked with FcR blocking antibodies in flow cytometry buffer (BD Biosciences, San Jose, CA) followed by incubation with isotype control or surface specific primary antibodies. Anti-CD11b (M1/70) PE-Cyanine7, anti-Ly6G (RB6-8c5) allophycocyanin-eFluor 780, anti-CD4 fluorescein isothiocyanate, anti-CD8 phosphatidylethanolamine, and antiB220 allophycocyanin were purchased from e-Biosciences (San Diego, CA). Cells were analyzed on a LSRII machine (BD Biosciences). Data were analyzed using the BD FACStation software (CellQuest Pro version 2.2.1, BD Biosciences). The total gated number of positive cells (approximately 30,000 events) was calculated as the percentage of total gated viable cells. Quadrants were assigned using isotype control monoclonal antibody. 

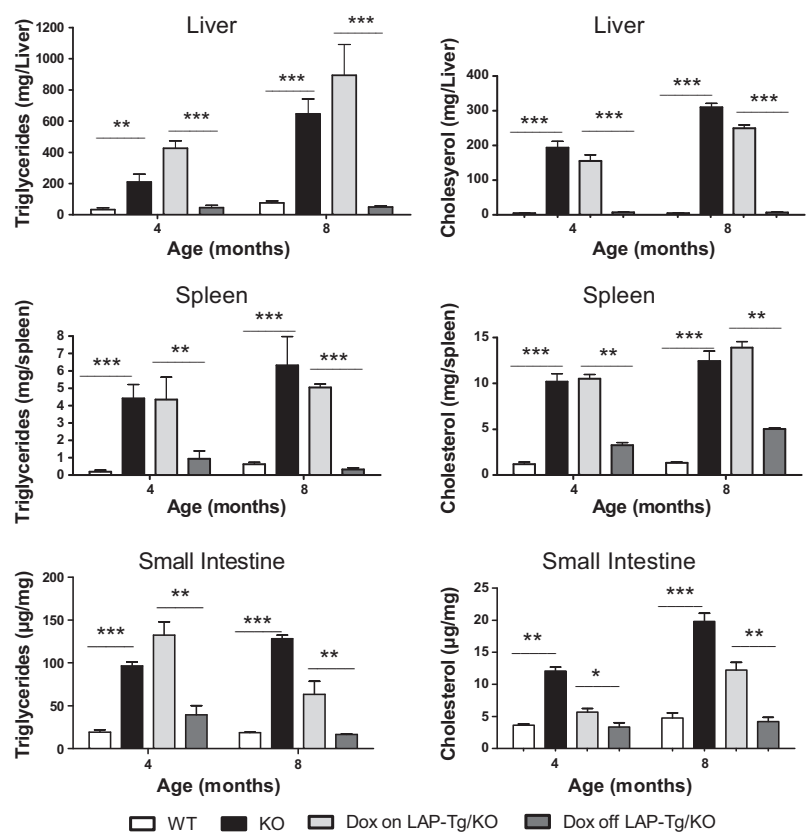

Figure 4 Quantitative analyses of cholesterol and triglycerides in the liver, spleen, and small intestine of human lysosomal acid lipase (hLAL) in liver-activated promoter (LAP) - driven tTA transgene and (tet0) ${ }_{7}$-CMV-hLAL transgene with $\mathrm{lal}^{-/-}(\mathrm{LAP}-\mathrm{Tg} / \mathrm{KO})$ mice. Concentrations of cholesterol and triglycerides in the liver, spleen, and small intestine of hLAL in LAP-Tg/KO mice were determined as described in Materials and Methods. Data are expressed as means \pm SEM from five mice in each group. ${ }^{\star} P<0.05$, ${ }^{* *} P<0.01$, and ${ }^{* * *} P<0.001$. WT, wild type.

\section{Mouse Metastasis Models}

For experimental metastasis, $5 \times 10^{5}$ B16 melanoma cells in $200 \mu \mathrm{L}$ of phosphate-buffered saline were injected into the mice via tail vein. Two weeks after the injection, the mice were sacrificed, and the livers and lungs were harvested for examination of metastasis.

\section{qPCR}

Total RNAs were purified from livers or isolated hepatocytes using RNeasy Mini Kits according to the manufacturer's instruction (Qiagen). Quantitative real-time RT-PCR (qPCR) was performed as described previously. ${ }^{22}$ Relative gene expression levels were analyzed using the $2^{-\Delta \Delta \mathrm{C}_{\mathrm{T}}}$ method. Primers of mouse IL-6, mouse granulocyte-macrophage colony-stimulating factor (GM-CSF), mouse macrophage colony-stimulating factor, mouse tumor necrosis factor (TNF)- $\alpha$, mouse IL-2, mouse IL-4, mouse IL-17, mouse interferon (IFN)- $\gamma$, mouse monocyte chemotactic protein-1 (MCP-1), mouse chemokine ligand (CCL)-3, mouse CCL4, mouse CCL5, mouse CXCL10, and glyceraldehyde-3-phosphate dehydrogenase for qPCR were described previously. ${ }^{23,24}$

\section{Cytokine Measurement by ELISA}

The expression levels of IL-6, GM-CSF, MCP-1 (BD Biosciences), and CCL5 (R\&D Systems, Minneapolis, MN) in the plasma and hepatocyte culture medium were measured using enzyme-linked immunosorbent assay (ELISA) kits according to the manufacturer's instructions.

\section{Mouse Hepatocyte Isolation}

Hepatocytes were isolated from the mouse using two-step perfusion and digestion technique described previously. ${ }^{25,26}$ Briefly, the hepatic portal perfusion of the mouse liver with $37^{\circ} \mathrm{C}$ prewarmed solution A $(0.5 \mathrm{mmol} / \mathrm{L}$ EGTA and $5 \mathrm{mmol} / \mathrm{L}$ HEPES in Hanks) was followed by digestion with $37^{\circ} \mathrm{C}$ prewarmed solution $\mathrm{B}\left(3.75 \mathrm{mmol} / \mathrm{L} \mathrm{CaCl}_{2}\right.$ and $0.05 \mathrm{mg} / \mathrm{mL}$ of collagenase $\mathrm{H}$ in L15) perfusion. The digested liver tissues were gently dispersed with tweezers, and hepatocytes were spun down and washed with $1 \times$ HEPES buffer. The cell pellets were resuspended in phosphate-buffered saline for flow cytometry. For tissue culture, isolated hepatocytes were resuspended in William's Medium E with $10 \%$ fetal bovine serum and cultured in $37^{\circ} \mathrm{C}$. After 2 hours, cells were replaced with new medium and prepared for cytokine and chemokine analyses of mRNA and protein expression.

\section{Statistical Analysis}

Data were expressed as means $\pm \mathrm{SD}$. Differences between the two treatment groups were compared with the $t$-test. When more than two groups were compared, one-way analysis of variance with post hoc Newman-Keul's multiple comparison test was used. Results were considered statistically significant when $P<0.05$. All analyses were performed with GraphPad Prism software version 5.0 (GraphPad, La Jolla, CA).
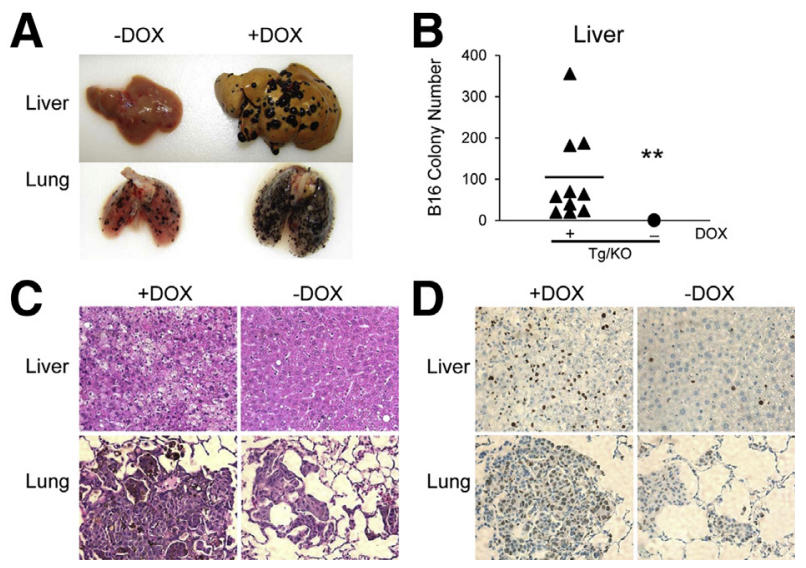

Figure 5 Hepatic expression of human lysosomal acid lipase ( $h L A L)$ in liver-activated promoter (LAP) - driven tTA transgene and (tet0) $)_{7}-\mathrm{CMV}$-hLAL transgene with $\mathrm{lal}^{-1-}$ (LAP-Tg/KO) mice reduces B16 melanoma metastasis. A: B16 melanoma cells $\left(5 \times 10^{5}\right)$ were intravenously injected into doxycycline-treated (+Dox) or doxycycline-untreated (-DOX) LAP-Tg/KO triple mice for 2 weeks. Metastasized B16 melanoma colonies in the liver and lung are shown. B: Quantitative analysis of B16 melanoma colonies in the livers of doxycycline-treated or doxycycline-untreated LAP-Tg/KO triple mice. C: Representative hematoxylin and eosin staining of liver and lung sections. D: Representative immunohistochemical staining of metastasized livers and lungs using anti-Ki67 antibody. $n=10$ to 16 (A and B). $* * P<0.01$. Original magnification: $\times 200$ (C and D). 

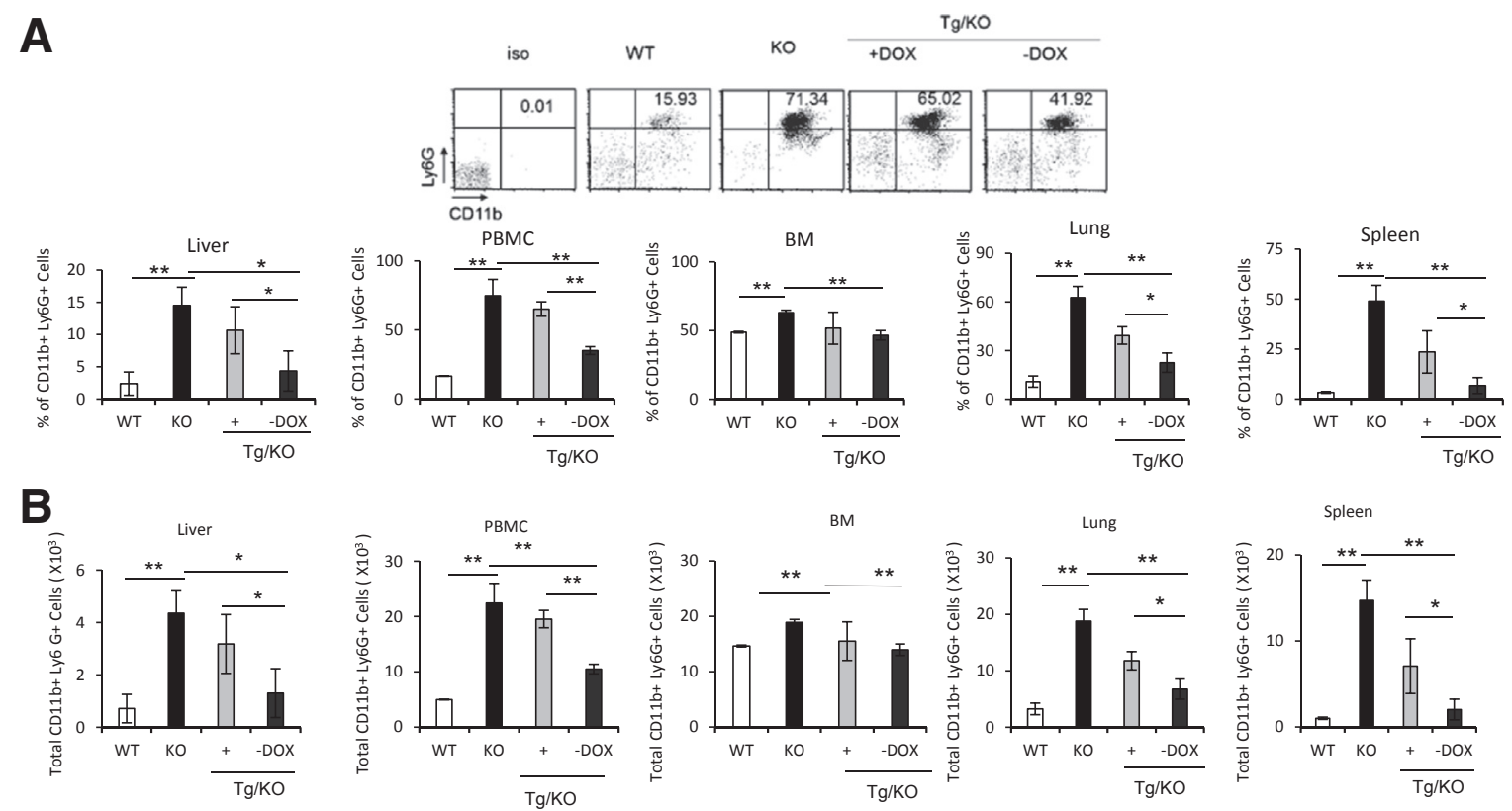

Figure 6 Hepatic expression of human lysosomal acid lipase ( $\mathrm{hLAL}$ ) in liver-activated promoter (LAP)-driven tTA transgene and (tet0) ${ }_{7}-\mathrm{CMV}$-hLAL transgene with $\mathrm{lal}^{-/}{ }^{-}(\mathrm{LAP}-\mathrm{Tg} / \mathrm{KO})$ mice reduces $\mathrm{CD}_{11 \mathrm{~b}}{ }^{+} \mathrm{Ly}_{6 \mathrm{G}}{ }^{+}$cell expansion. The percentages $(\mathbf{A})$ and total cell numbers $(\mathbf{B})$ of $\mathrm{CD} 11 \mathrm{~b}^{+} \mathrm{Ly} 6 \mathrm{G}^{+}$cells in the wild-type (WT), lal ${ }^{-\prime}(\mathrm{KO})$, doxycycline-treated (+DOX), or doxycycline-untreated (-DOX) LAP-Tg/KO liver, bone marrow (BM), blood [peripheral blood mononuclear cells $(\mathrm{PBMCS})]$, lung, and spleen $\left(3 \times 10^{4}\right)$. A representative dot plot of $\mathrm{CD}_{11 \mathrm{~b}^{+} \text {Ly6G }}{ }^{+}$cells in the blood is shown. Data are expressed as means \pm SD from four mice in each group. $n=4 .{ }^{*} P<0.05,{ }^{* *} P<0.01$.

\section{Results}

Hepatocyte-Specific Expression of hLAL in $l a l^{-/-}$Mice

Specific expression of hLAL mRNA in the liver of doxycycline-untreated LAP-Tg/KO triple mice was confirmed by RT-PCR. Two sets of hLAL primers covering different ranges of hLAL cDNA were used to distinguish hLAL expression from endogenous murine LAL expression. One pair of primers covered exons 8 to 9 of hLAL (Figure 1, A and B), whereas another pair of primers covered exon 9 of hLAL and the Flag epitope coding sequence at the $3^{\prime}$ end of hLAL cDNA in the (tetO) $)_{7}$-CMV-hLAL vector, which is unique to the hLAL-Flag combination (Figure 1, A and B). As predicted, no hLAL mRNA expression was detected in the liver, lung, spleen, and bone marrow cells of wild-type, $\mathrm{lal}^{-/-}$, and doxycycline-treated (turned off) $\mathrm{LAP}-\mathrm{Tg} / \mathrm{KO}$ triple mice. When doxycycline was removed from this Tet-off system, hLAL mRNA expression was induced primarily in the liver of LAP-Tg/KO triple mice (Figure 1A). To further confirm hLAL mRNA expression in hepatocytes of the liver, hepatocyte and $\mathrm{Ly}_{6 \mathrm{G}}^{+}$myeloid cells were isolated from the liver of wild-type and doxycycline-untreated LAP-Tg/KO mice. Indeed, hLAL mRNA expression was detected in hepatocytes but not in $\mathrm{Ly}_{6 \mathrm{G}}^{+}$cells of $\mathrm{LAP}-\mathrm{Tg} / \mathrm{KO}$ triple mice. No detection was observed in hepatocyte and $\mathrm{Ly} 6 \mathrm{G}^{+}$cells of wild-type mice (Figure 1B).

Next, LAL protein expression was also evaluated. Because hLAL and murine LAL share $75 \%$ identity and $95 \%$ similarity at the peptide sequence level, our anti-LAL antibody recognizes both of them. In wild-type mice, expression of the LAL protein was detected in the liver, lung, spleen and bone marrow but was undetectable in $\mathrm{KO}$ mice (Figure 1C). In $\mathrm{LAP}-\mathrm{Tg} / \mathrm{KO}$ triple mice, expression of the $\mathrm{hLAL}$ protein was detected strongly in the liver and weakly in the lung and spleen of doxycycline-untreated LAP-Tg/KO triple mice but not in doxycycline-treated $\mathrm{LAP}-\mathrm{Tg} / \mathrm{KO}$ triple mice (Figure 1C). To further clarify the cellular specificity of hLAL protein in the liver, immunohistochemical (IHC) staining of the liver sections with anti-LAL antibody and anti-F4/80 antibody were performed. The results revealed that approximately $50 \%$ of hepatocytes were positive for LAL antibody staining, and $\mathrm{F} 4 / 80^{+}$Kupffer cells were also positive for LAL staining (Figure 1D) in doxycycline-untreated LAP-Tg/ KO mice. Because LAL is a secreted protein, the lack of hLAL mRNA expression for the detection of LAL protein in the lung and spleen of doxycycline-untreated LAP-Tg/KO triple mice is likely due to the uptake of LAL from the circulation system that is secreted from the liver. However, the possibility of uptake of LAL from circulation that is secreted from the liver needs to be further confirmed. The multiple forms of LAL protein were due to differential glycosylation as previously reported. $^{27,28}$

Hepatocyte-Specific Expression of hLAL in lal $^{-/-}$Mice Reduces Lipid Storage in Multiple Organs

Hepatomegaly is the major symptom in patients with WD and CESD. Characterization of $\mathrm{lal}^{-/-}$mice revealed neutral 

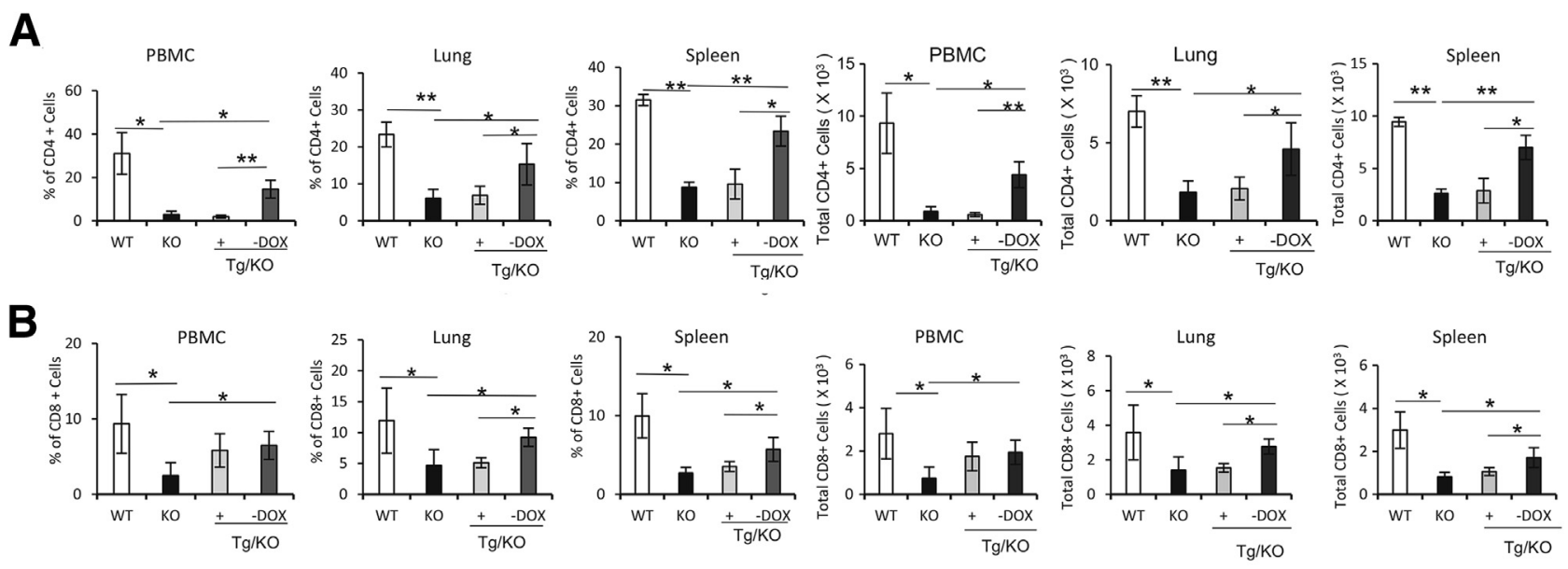

C
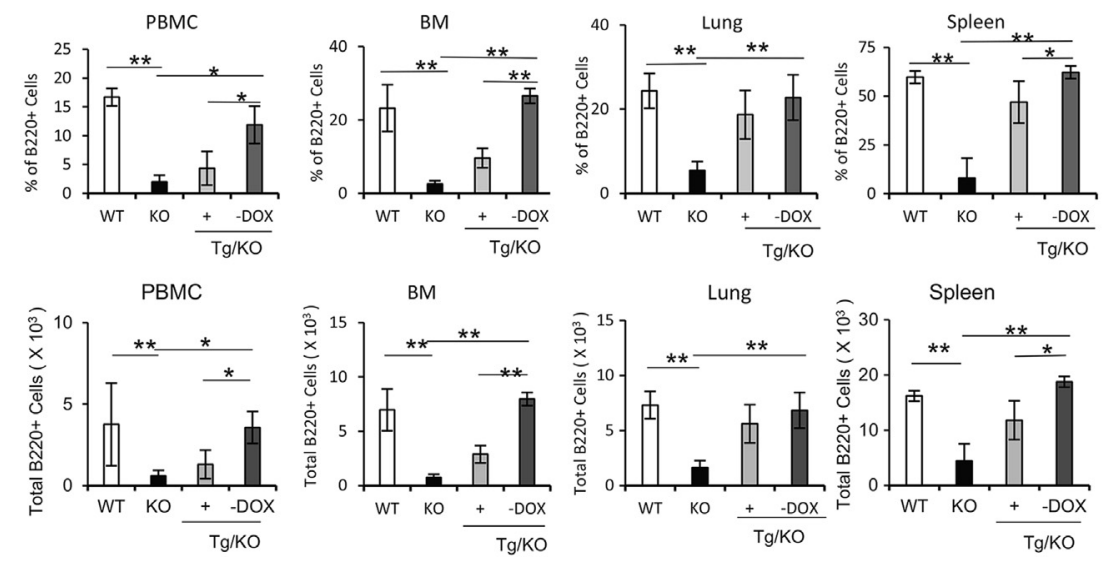

Figure 7 Hepatic expression of human lysosomal acid lipase ( $\mathrm{hLAL}$ ) in liver-activated promoter (LAP)-driven tTA transgene and (tet0) 7 -CMV-hLAL transgene with lal ${ }^{-1-}(\mathrm{LAP}-\mathrm{Tg} / \mathrm{KO})$ mice increases $\mathrm{CD} 4^{+}, \mathrm{CD} 8^{+}$, and $\mathrm{B220^{+ }}$ cells. The percentages and total cell numbers of $\mathrm{CD} 4^{+} \mathrm{T}$ cells $(\mathrm{A}), \mathrm{CD} 8^{+} \mathrm{T}$ cells $(\mathbf{B})$, and $\mathrm{B}_{220^{+}} \mathrm{B}$ cells $(\mathrm{C})$ in the wild-type (WT), lal ${ }^{-/-}(\mathrm{KO})$, doxycycline-treated (+DOX), or doxycycline-untreated (-DOX) LAP-Tg/KO bone marrow (BM), blood [peripheral blood mononuclear cells (PBMCs)], lung, and spleen. Representative dot plots or histograms of $\mathrm{CD}^{+}{ }^{+}, \mathrm{CD}^{+}{ }^{+}$, and B220 ${ }^{+}$cells in the blood (PBMCs) are shown, respectively. Data are expressed as means \pm SD from four mice in each group. $n=4$. ${ }^{*} P<0.05$, ${ }^{* *} P<0.01$.

lipid storage in both hepatocytes and Kupffer cells in the liver. $^{7,8}$ In the tet-off LAP-Tg/KO system, both gross view and the histologic phenotypes of the liver, spleen, and small intestine in doxycycline-treated LAP- $\mathrm{Tg} / \mathrm{KO}$ triple mice (for 7 months) were essentially similar to those in $l a l^{-/-}$mice (Figure 2, A, C, D, G, H, K, and L). Doxycycline-untreated LAP-Tg/KO triple mice, in which hLAL expression was induced, lacked lipid storage not only in hepatocytes but also in Kupffer cells (Figure 2E) similar to the wild-type liver (Figure 2B). The same observations were found in the spleen and small intestine (Figure 2, I and M), resembling those of wild-type mice (Figure 2, F and J). Neutral lipid staining by Oil Red-O revealed that doxycyclinetreated $\mathrm{LAP}-\mathrm{Tg} / \mathrm{KO}$ triple mice have the similar level of neutral lipid storage in the liver, spleen, and small intestine compared with those of $l a l^{-/-}$mice (Figure 3, B, C, F, G, J, and $\mathrm{K}$ ). Doxycycline-untreated LAP-Tg/KO triple mice had no lipid storage in the liver, spleen, or small intestine similar to those of wild-type mice (Figure 3, A, D, E, H, I, and L). Quantitative analyses of cholesterol and triglyceride tissue lipids in the liver, spleen, and small intestine further confirmed that lipid storage in $l a l^{-/-}$mice was completely cleaned up by hepatocyte expression of hLAL (Figure 4).

\section{Hepatocyte-Specific Expression of hLAL in lal $^{-/-}$Triple Mice Reduces B16 Melanoma Cell Metastasis}

We recently reported that LAL deficiency facilitates inflammation-induced tumor progression and metastasis in the liver and lung. ${ }^{24}$ To evaluate the effects of hLAL in hepatocytes on tumor metastasis, B16 melanoma cells were injected into the tail veins of LAP-Tg/KO triple mice to assess the metastatic potential. Two weeks after injection, more B16 melanoma colonies were observed in the livers and lungs of doxycycline-treated LAP-Tg/KO triple mice compared with those in untreated mice with statistical significance (Figure 5, A and B). Hematoxylin and eosin (H\&E) and IHC staining of liver and lung sections revealed more neoplastic melanoma cells and Ki-67 positive proliferative cells in doxycyclinetreated $\mathrm{LAP}-\mathrm{Tg} / \mathrm{KO}$ triple mice than those from untreated mice (Figure 5, C and D). Taken together, these observations 


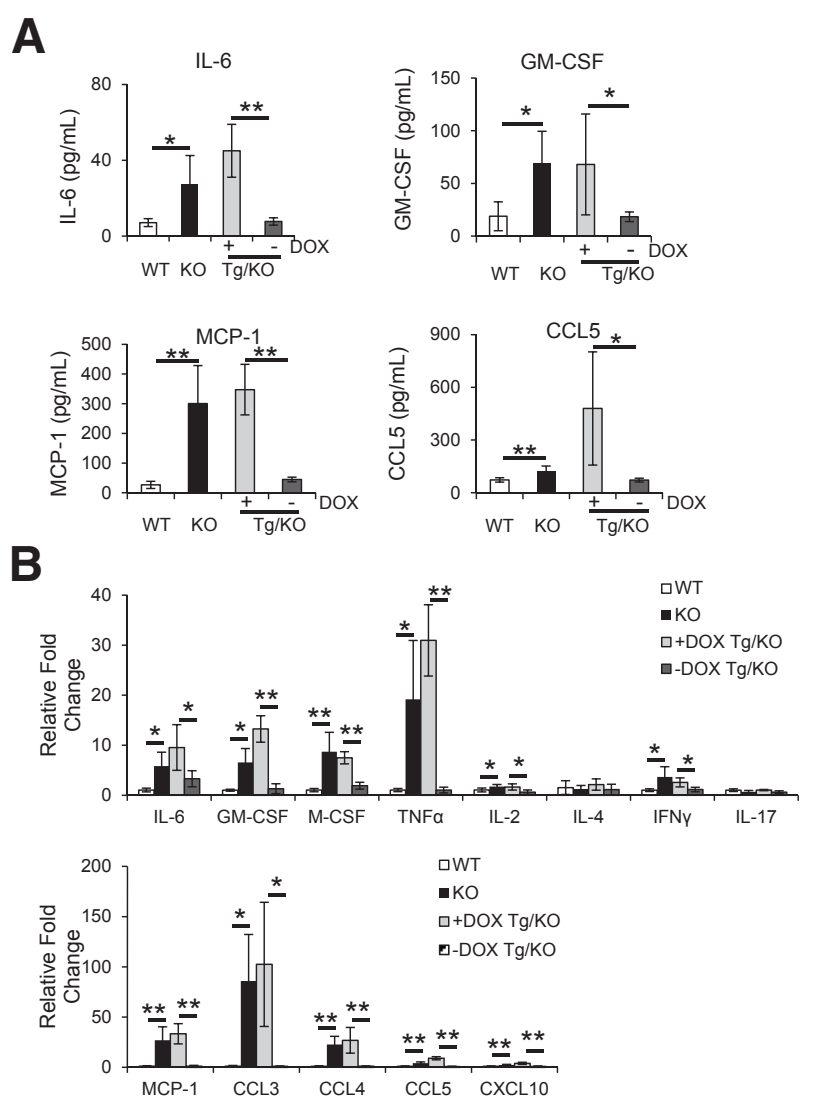

Figure 8 Hepatic expression of human lysosomal acid lipase ( $h L A L)$ in liver-activated promoter (LAP)-driven tTA transgene and (tet0) ${ }_{7}$-CMV-hLAL transgene with $\mathrm{lal}^{-/-}$(LAP-Tg/KO) mice reduces synthesis and secretion of cytokines and chemokines. A: The concentrations of IL-6, granulocytemacrophage colony-stimulating factor (GM-CSF), monocyte chemotactic protein-1 (MCP-1), and chemokine ligand (CCL)-5 in the plasma of doxycycline-treated $(+\mathrm{DOX})$ or doxycycline-untreated $(-\mathrm{DOX}) \mathrm{lal}^{+/+}$[wild type (WT) ], lal ${ }^{-1-}(\mathrm{K} 0)$, and LAP-Tg/KO mice were determined by enzymelinked immunosorbent assay. B: Quantitative real-time PCR analyses of mRNA expression levels of cytokines and chemokines in the liver of $\mathrm{lal}^{+/+}$ (WT), $\mathrm{lal}^{-{ }^{-}}(\mathrm{KO})$, and +DOX or $-\mathrm{DOX} \mathrm{LAP}-\mathrm{Tg} / \mathrm{KO}$ mice. The relative gene expression was normalized to glyceraldehyde-3-phosphate dehydrogenase mRNA, and analysis was performed by the $2^{-\Delta \Delta C_{T}}$ method. Data are expressed as means \pm SD. $n=5$ to 6 (A); $n=4$ (B). ${ }^{*} P<0.05$, ${ }^{* *} P<0.01$. IFN $\gamma$, interferon- $\gamma$; TNF $\alpha$, tumor necrosis factor- $\alpha$.

suggest that hepatocyte-specific expression of hLAL in $l a l^{-/}$ mice reduced B16 melanoma cell metastasis.

Hepatocyte-Specific Expression of hLAL in lal $^{-/-}$Triple Mice Decreases Abnormal Expansion of CD11b ${ }^{+}$Ly6G $^{+}$ Cells

Previous studies have found that loss of LAL causes significant

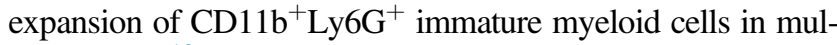
tiple organs. ${ }^{10}$ When tested in the liver, this cell population was also markedly increased in $l a l^{-1-}$ mice (Figure 6). To test whether hLAL expression in hepatocyte reversed this phenotype, the $\mathrm{LAP}-\mathrm{Tg} / \mathrm{KO}$ triple mice were treated with or without doxycycline for 6 to 7 months. Age-matched wild-type and $\mathrm{lal}^{-1-}$ mice were used as controls. Cells from the bone marrow, blood, spleen, lung, and liver of four groups were isolated and stained with anti-CD11b and anti-Ly6G antibodies for flow cytometry analysis. In the liver, the percentage and total number

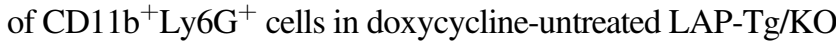
triple mice were decreased to the levels of wild-type mice (Figure 6, A and B). With doxycycline treatment, hLAL expression was shut down in LAP-Tg/KO hepatocytes, which led to $\mathrm{CD} 11 \mathrm{~b}^{+} \mathrm{Ly}_{6 \mathrm{G}}{ }^{+}$cell expansion to the level observed in $l a l^{-1-}$ mice. Because hLAL is a secretory enzyme, reduction of $\mathrm{CD} 11 \mathrm{~b}^{+} \mathrm{Ly}_{6 \mathrm{G}}^{+}$cell expansion was also observed in the blood, spleen, and lung but not in the bone marrow of doxycyclineuntreated $\mathrm{LAP}-\mathrm{Tg} / \mathrm{KO}$ triple mice (Figure 6, A and B).

\section{Hepatocyte-Specific Expression of hLAL in $\mathrm{lal}^{-/-}$Triple Mice Increases $\mathrm{CD}_{4}^{+}, \mathrm{CD}^{+}$, and $\mathrm{B} 220^{+}$Cells}

$\mathrm{CD} 11 \mathrm{~b}^{+} \mathrm{Ly} 6 \mathrm{G}^{+}$cells are partially responsible for the decrease of $\mathrm{CD}^{+}$and $\mathrm{CD}^{+}{ }^{\mathrm{T}}$ cells in $l a l^{-/-}$mice. ${ }^{9}$ It is intriguing to determine whether a decrease of $\mathrm{CD} 11 \mathrm{~b}^{+} \mathrm{Ly}_{6 \mathrm{G}}{ }^{+}$cells in doxycycline-untreated LAP- $\mathrm{Tg} / \mathrm{KO}$ triple mice leads to an increase of $\mathrm{CD}^{+}{ }^{+}$and $\mathrm{CD} 8^{+} \mathrm{T}$ cells. The $\mathrm{CD} 4^{+} \mathrm{T}$-cell level was low in doxycycline-treated LAP- $\mathrm{Tg} / \mathrm{KO}$ triple mice, which is similar to that of $\mathrm{lal}^{-/-}$mice. However, hLAL hepatocytespecific expression increased $\mathrm{CD}^{+} \mathrm{T}$ cells in LAP-Tg/KO triple mice in the blood, lung, and spleen (Figure 7A). CD8 ${ }^{+}$ $\mathrm{T}$ cells had a similar outcome in the lung and spleen but not in the blood (Figure 7B). The result for the B220 $0^{+}$B-cell population was similar to those observed in T-cell populations (Figure 7C). Because of the overlap and interference of strong autofluorescence from liver cells of $l a l^{-/}$mice, the T-cell and B-cell levels in the liver were unable to be determined by flow cytometry.

\section{Hepatocyte-Specific Expression of hLAL in lal $^{-/-}$ Triple Mice Reduces Synthesis and Secretion of Tumor-Promoting Cytokines and Chemokines}

In addition to the changes of immune cells, cytokines and chemokines that are known to promote inflammation and tumorigenesis were measured in the blood plasma by ELISA. The plasma concentrations of IL-6, GM-CSF, MCP-1, and CCL5 were decreased in untreated LAP-Tg/KO triple mice compared with those in doxycycline-treated mice (Figure 8A). These cytokines and chemokines are important for MDSC accumulation and tumorigenesis. ${ }^{29,30}$ mRNA syntheses of these cytokines and chemokines in the liver were further investigated. mRNA levels of IL-6, GM-CSF, M-CSF, and TNF- $\alpha$ were significantly down-regulated in the liver of doxycycline-untreated LAP-Tg/KO triple mice, accompanied by reduced mRNA levels of T-cell-secreted lymphokines IL-2 and IFN- $\gamma$, and unchanged IL-4 and IL17 levels (Figure 8B). In addition, mRNA syntheses of chemokines that have been reported to be involved in liver injury $^{31}$ were markedly down-regulated in the livers of doxycycline-untreated LAP-Tg/KO triple mice, including MCP-1, CCL3, CCL4, CCL5, and CXCL10. Therefore, 


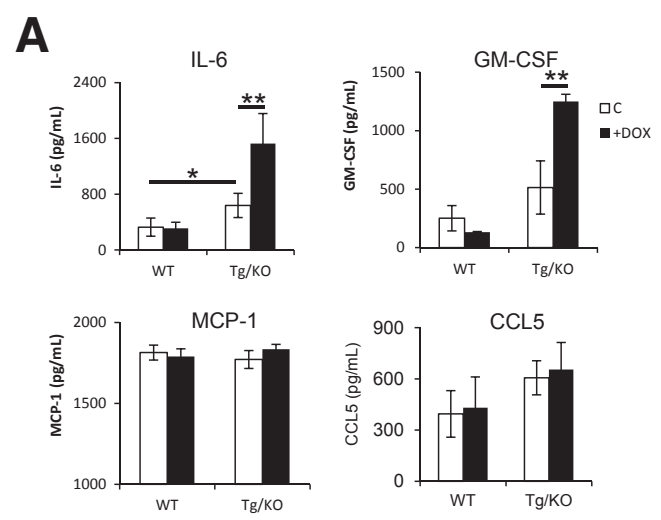

B
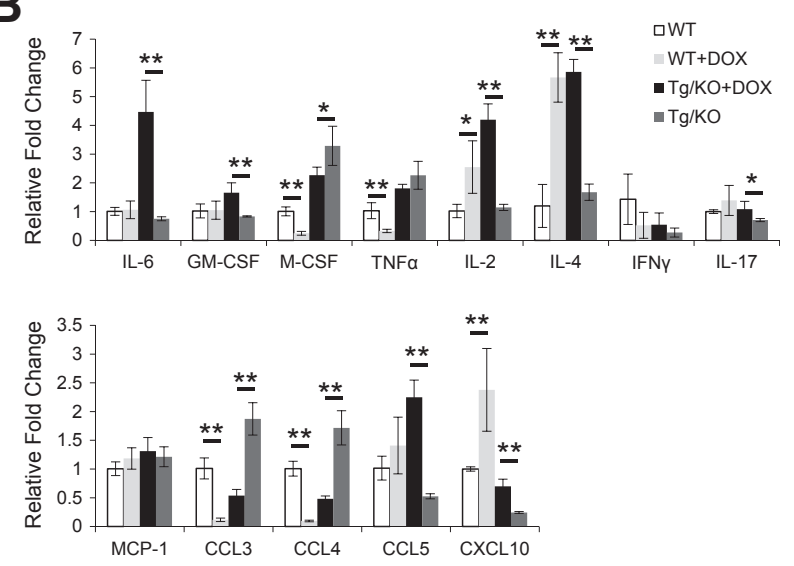

Figure 9 In vitro doxycycline treatment of primary hepatocytes from untreated liver-activated promoter (LAP)-driven tTA transgene and (tet0) ${ }_{7}-\mathrm{CMV}$-hLAL transgene with $\mathrm{lal}^{-{ }^{-}-}$( $\left.\mathrm{LAP}-\mathrm{Tg} / \mathrm{KO}\right)$ triple mice induces synthesis and secretion of inflammatory cytokines and chemokines. Hepatocytes isolated from $\mathrm{lal}^{+/+}$[wild type (WT)] and doxycycline-untreated $\mathrm{LAP}-\mathrm{Tg} / \mathrm{KO}$ triple mice were treated with doxycycline in vitro for 5 days. A: The concentrations of IL-6, granulocyte-macrophage colony-stimulating factor (GM-CSF), monocyte chemotactic protein-1 (MCP-1), and chemokine ligand (CCL)- 5 in the culture medium were determined by enzymelinked immunosorbent assay. B: Quantitative real-time PCR analyses of mRNA expression levels of cytokines and chemokines in the isolated hepatocytes of $\mathrm{lal}^{+/+}$(WT) and LAP-Tg/KO mice treated with or without doxycycline. The relative gene expression was normalized to glyceraldehyde-3-phosphate dehydrogenase mRNA, and analyses were performed by the $2^{-\Delta \Delta C_{\mathrm{T}}}$ method. Data are expressed as means \pm SD. $n=4$. ${ }^{*} P<0.05$, ${ }^{* *} P<0.01$. IFN $\gamma$, interferon $-\gamma ; \operatorname{TNF} \alpha$, tumor necrosis factor- $\alpha$.

reduced synthesis and secretion of cytokines and chemokines were, at least in part, responsible for the decreased metastasis in the $\mathrm{lal}^{-/-}$mice with hepatocyte-specific hLAL expression. These cytokines may or may not be synthesized and secreted by hepatocytes, which were tested below.

\section{In Vitro Doxycycline Treatment of Hepatocytes from Untreated LAP-Tg/KO Triple Mice Induces Synthesis and Secretion of Inflammatory Cytokines and Chemokines}

To determine which of these tumor-promoting cytokines are secreted by hepatocytes of LAP-Tg/KO triple mice, hepatocytes were isolated from $\mathrm{lal}^{+/+}$and doxycyclineuntreated $\mathrm{LAP}-\mathrm{Tg} / \mathrm{KO}$ triple mice, followed by treatment with doxycycline in vitro for 5 days. The culture medium was harvested and cytokine levels were determined by ELISA. The concentrations of GM-CSF and IL- 6 in the culture medium of doxycycline-treated $\mathrm{LAP}-\mathrm{Tg} / \mathrm{KO}$ hepatocytes were significantly increased, whereas MCP-1 and CCL5 did not change, compared with those from untreated hepatocytes (Figure 9A). This observation suggests that doxycyclineinducible hLAL off-expression in hepatocytes partially contributes to the increased concentrations of GM-CSF and IL- 6 but not those of MCP-1 and CCL5. mRNA syntheses of these cytokines/chemokines in the hepatocytes were further investigated. mRNA levels of IL-6, GM-CSF, IL-2, IL-4, IL-17, CCL5, and CXCL10 were significantly up-regulated in the doxycycline-treated LAP-Tg/KO hepatocytes, accompanied by reduced mRNA levels of M-CSF, CCL3, and CCL4, and no change of TNF- $\alpha$, IFN- $\gamma$, and MCP-1 (Figure 9B). The increased synthesis of IL-6, GM-CSF, IL-2, CCL5, and CXCL10 in doxycycline-treated LAP-Tg/KO hepatocytes was similar to that observed in the whole liver of doxycyclinetreated $\mathrm{LAP}-\mathrm{Tg} / \mathrm{KO}$ triple mice, suggesting that the changes of these cytokines and chemokines syntheses were mainly contributed by hepatocytes, whereas the syntheses of other cytokines and chemokines were contributed by other cell types in the liver.

\section{Discussion}

There are two major cell populations in the liver, hepatocytes and Kupffer cells (macrophages), which work together to maintain liver homeostasis and function. Imbalance of neutral lipid metabolism controlled by LAL in these two cell populations contributes greatly to various liver diseases. Accumulation of neutral lipids (as evident by Oil Red-O staining) in $l a l^{-/-}$hepatocytes and myeloid cells results in major liver malformation with significantly enlarged yellowish mass, destruction of the anatomy structure (Figure 2), and massive MDSC infiltration (Figure 6). ${ }^{13}$ Two transgenic lines have been designed to evaluate the functional roles of LAL in hepatocytes versus myeloid cells.

We have previously established a myeloid-specific hLAL expression mouse model to rescue the myeloid LAL deficiency in c-fms-rtTA/(tetO) $)_{7}-\mathrm{CMV}-\mathrm{hLAL} ; \mathrm{lal}^{-/-}$triple mice (named c-fms-Tg/KO mice). ${ }^{13}$ The myeloid cell-specific expression of hLAL in c-fms- $\mathrm{Tg} / \mathrm{KO}$ mice has approximately $60 \%$ of the wild-type LAL activity level in the liver. The expression of hLAL in the myeloid cells mainly corrected the lipid storage in the Kupffer cells and only partially corrected the lipid storage in the liver and small intestine. ${ }^{13}$ The expression of hLAL in the myeloid cells reduced myeloid cell infiltration in the liver and other organs. ${ }^{11,13}$ Further characterization of c-fms-Tg/KO mice revealed that the myeloid expression of hLAL reverses the elevated level of MDSCs starting from the early developing stage of granular myeloid progenitor cells in the bone marrow. 
Myeloid expression of hLAL in c-fms-Tg/KO mice partially reversed inhibition of $\mathrm{CD}^{+}{ }^{+}$and $\mathrm{CD} 8^{+} \mathrm{T}$-cell development in the thymus and maturation in the spleen. ${ }^{11}$

In comparison, this study found that hLAL-specific expression in the hepatocytes almost completely corrected liver malformation in LAP-Tg/KO mice (Figure 2) and myeloid cell infiltration (Figure 3, C, D, G, H, K, and L). Simultaneously, it reduced production of proinflammatory cytokines and chemokines and the MDSC level (Figures 6, 8, and 9), which resulted in recovery of T-cell and B-cell populations in the liver (Figure 7). Interestingly, hLAL-specific expression in the hepatocytes reduced MDSCs and increased T-cell and B-cell populations in other organs as well (Figures 6 and 7). This observation indicates that hLAL made in the liver is secreted into the circulation system and affects distant organs. LAL deficiency in both residential hepatocytes and myeloid cells is responsible for liver disease formation. Notably, the mouse version and the human version of LAL are functionally interchangeable in animal models. These animal models (LAP-Tg/ $\mathrm{KO}$ mice, c-fms- $\mathrm{Tg} / \mathrm{KO}$ mice) with overexpression of human LAL will greatly benefit LAL human research.

In addition to WD and CESD, patients with mutations in the $L A L$ gene have been reported to associate with liver carcinogenesis. ${ }^{32}$ When tested in the $l a l^{-/}$mouse model, we have recently discovered that LAL deficiency-induced inflammation plays crucial roles at all stages of tumor development. ${ }^{24}$ In $\mathrm{lal}^{-1-}$ mice, B16 melanoma metastasized in the liver and lung of allogeneic $l a l^{-/-}$mice, which was suppressed in allogeneic $\mathrm{lal}^{+/+}$mice due to immune rejection. Interestingly and importantly, in addition to the immune suppressive function, we found that MDSCs from $\mathrm{lal}^{-/-}$mice alone directly stimulated B16 melanoma cell in vitro proliferation and in vivo growth and metastasis. ${ }^{24}$ Cytokines (ie, IL-1 $\beta$, IL- 6 , and TNF- $\alpha$ ) from $l a l^{-/-}$MDSCs are required for B16 melanoma proliferation. ${ }^{24}$ In addition to MDSCs, it seems that hepatocytes were also responsible for production of tumor-promoting cytokines as found here. hLAL-specific expression in the hepatocytes reduced expression of tumor-promoting cytokines (Figures 8 and 9), as well as MDSCs (Figure 6). Taken together, both immune cells and tumor-promoting cytokines contribute to tumor growth and metastasis in allogeneic $\mathrm{lal}^{-/-}$mice. As a consequence, B16 melanoma metastasis was almost completely blocked in the liver of allogeneic LAP-Tg/KO mice, an indication of recovery of immune rejection to tumor cells. Importantly, reduction of B16 melanoma metastasis in the distant organ lung was also observed by hLAL-specific expression in the hepatocytes (Figure 5).

In summary, LAL in hepatocytes plays critical roles in maintaining liver homeostasis and function. The molecular mechanisms that mediate LAL functions in hepatocytes can be two-fold. First, the derivatives of free fatty acid metabolites serve as hormonal ligands for peroxisome proliferator-activated receptor gamma (PPAR $\gamma$ ). Activation of PPAR $\gamma$ by these ligands inhibits proinflammatory molecule (TNF- $\alpha, \mathrm{IL}-1 \beta$, and IL-6) production ${ }^{33-35}$ and induces MDSC expansion. ${ }^{22}$ PPAR $\gamma$ ligand treatment improves the pathogenic phenotypes in the lungs of $l a l^{-/}$mice. ${ }^{36}$ Second, Affymetrix GeneChip microarray analysis and Ingenuity Pathway Analysis identified the mammalian target of rapamycin (mTOR) as a major signaling pathway in mediating $\mathrm{lal}^{-1-}$ MDSCs malfunctions, including immunosuppression and tumor stimulation. ${ }^{37}$ Membrane trafficking causes mTOR to shuttle to lysosomes and regulate mTOR signaling. ${ }^{38,39}$ The role of PPAR $\gamma$ and mTOR pathways in mediating LAL functions needs to be explored further.

\section{Acknowledgments}

We thank Katlin L. Walls and Michele Klunk for animal maintenance and genotyping and editing the manuscript.

\section{References}

1. Grabowski GA, Du H, Charnas L: Lysosomal acid lipase deficiencies: the wolman disease/cholesteryl ester storage disease spectrum. Edited by Valle D, Voglstein B, Kinzler KW, Antonarakis SE, Ballabio A. The Online Metabolic and Molecular Bases of Inherited Disease (OMMBID). ed 9. New York, McGraw-Hill, 2012

2. Assmann G, Seedorf U: Metabolic and Molecular Bases of Inherited Diseases. 8th Edition. New York, McGraw-Hill, 2001

3. Yan C, Du H: Lysosomal acid lipase is critical for myeloid-derived suppressive cell differentiation, development, and homeostasis. World J Immunol 2014, 4:42-51

4. Beaudet AL, Ferry GD, Nichols BL Jr, Rosenberg HS: Cholesterol ester storage disease: clinical, biochemical, and pathological studies. J Pediatr 1977, 90:910-914

5. Bernstein DL, Hulkova H, Bialer MG, Desnick RJ: Cholesteryl ester storage disease: review of the findings in 135 reported patients with an underdiagnosed disease. J Hepatol 2013, 58:1230-1243

6. Fouchier SW, Defesche JC: Lysosomal acid lipase A and the hypercholesterolaemic phenotype. Curr Opin Lipidol 2013, 24 332-338

7. Du H, Duanmu M, Witte D, Grabowski GA: Targeted disruption of the mouse lysosomal acid lipase gene: long-term survival with massive cholesteryl ester and triglyceride storage. Hum Mol Genet 1998, 7: $1347-1354$

8. Du H, Heur M, Duanmu M, Grabowski GA, Hui DY, Witte DP, Mishra J: Lysosomal acid lipase-deficient mice: depletion of white and brown fat, severe hepatosplenomegaly, and shortened life span. J Lipid Res 2001, 42:489-500

9. Qu P, Du H, Wilkes DS, Yan C: Critical roles of lysosomal acid lipase in T cell development and function. Am J Pathol 2009, 174:944-956

10. Qu P, Shelley WC, Yoder MC, Wu L, Du H, Yan C: Critical roles of lysosomal acid lipase in myelopoiesis. Am J Pathol 2010, 176: 2394-2404

11. Qu P, Yan C, Blum JS, Kapur R, Du H: Myeloid-specific expression of human lysosomal acid lipase corrects malformation and malfunction of myeloid-derived suppressor cells in lal-/- mice. J Immunol 2011, 187: 3854-3866

12. Lian X, Yan C, Yang L, Xu Y, Du H: Lysosomal acid lipase deficiency causes respiratory inflammation and destruction in the lung. Am J Physiol Lung Cell Mol Physiol 2004, 286:L801-L807

13. Yan C, Lian X, Li Y, Dai Y, White A, Qin Y, Li H, Hume DA, Du H: Macrophage-specific expression of human lysosomal acid lipase corrects inflammation and pathogenic phenotypes in lal-/- mice. Am J Pathol 2006, 169:916-926

14. Rothe G, Stohr J, Fehringer P, Gasche C, Schmitz G: Altered mononuclear phagocyte differentiation associated with genetic defects of the lysosomal acid lipase. Atherosclerosis 1997, 130:215-221 
15. Elinav E, Nowarski R, Thaiss CA, Hu B, Jin C, Flavell RA: Inflammation-induced cancer: crosstalk between tumors, immune cells and microorganisms. Nat Rev Cancer 2013, 13:759-771

16. Berasain C, Castillo J, Perugorria MJ, Latasa MU, Prieto J, Avila MA: Inflammation and liver cancer: new molecular links: steroid enzymes and cancer. Ann N Y Acad Sci 2009, 1155:206-221

17. Solito S, Marigo L, Pinton L, Damuzzo V, Mandruzzato S, Bronte V: Myeloid-derived suppressive cells heterogeneity in human cancers. Ann N Y Acad Sci 2014, 1319:47-65

18. Li Y, Qin Y, Li H, Wu R, Yan C, Du H: Lysosomal acid lipase overexpression disrupts lamellar body genesis and alveolar structure in the lung. Int J Exp Pathol 2007, 88:427-436

19. Folch J, Lees M, Sloane SS: A simple method for isolation and purification of otal lipids from animal tissues. J Biol Chem 1957, 125:497-509

20. Du H, Schiavi S, Levine M, Mishra J, Heur M, Grabowski GA: Enzyme therapy for lysosomal acid lipase deficiency in the mouse. Hum Mol Genet 2001, 10:1639-1648

21. Qu P, Du H, Li Y, Yan C: Myeloid-specific expression of Api6/AIM/Sp alpha induces systemic inflammation and adenocarcinoma in the lung. J Immunol 2009, 182:1648-1659

22. Wu L, Yan C, Czader M, Foreman O, Blum JS, Kapur R, Du H: Inhibition of PPARgamma in myeloid-lineage cells induces systemic inflammation, immunosuppression, and tumorigenesis. Blood 2012, 119:115-126

23. Qu P, Du H, Wang X, Yan C: Matrix metalloproteinase 12 overexpression in lung epithelial cells plays a key role in emphysema to lung bronchioalveolar adenocarcinoma transition. Cancer Res 2009, 69:7252-7261

24. Zhao T, Du H, Ding X, Walls K, Yan C: Activation of mTOR pathway in myeloid-derived suppressor cells stimulates cancer cell proliferation and metastasis in lal mice. Oncogene 2014, 34:1938-1948

25. Klaunig JE, Goldblatt PJ, Hinton DE, Lipsky MM, Chacko J, Trump BF: Mouse liver cell culture. I. Hepatocyte isolation. In Vitro 1981, 17:913-925

26. Klaunig JE, Goldblatt PJ, Hinton DE, Lipsky MM, Trump BF: Mouse liver cell culture, II: primary culture. In Vitro 1981, 17:926-934

27. Sando GN, Rosenbaum LM: Human lysosomal acid lipase/cholesteryl ester hydrolase: purification and properties of the form secreted by fibroblasts in microcarrier culture. J Biol Chem 1985, 260: 15186-15193
28. Zschenker O, Bahr C, Hess UF, Ameis D: Systematic mutagenesis of potential glycosylation sites of lysosomal acid lipase. J Biochem 2005, 137:387-394

29. Wu L, Du H, Li Y, Qu P, Yan C: Signal transducer and activator of transcription 3 (Stat3C) promotes myeloid-derived suppressor cell expansion and immune suppression during lung tumorigenesis. Am J Pathol 2011, 179:2131-2141

30. Balkwill F: Cancer and the chemokine network. Nat Rev Cancer 2004, 4:540-550

31. Li K, Li NL, Wei D, Pfeffer SR, Fan M, Pfeffer LM: Activation of chemokine and inflammatory cytokine response in hepatitis $\mathrm{C}$ virus-infected hepatocytes depends on Toll-like receptor 3 sensing of hepatitis C virus double-stranded RNA intermediates. Hepatology 2012, 55:666-675

32. Elleder M, Chlumska A, Hyanek J, Poupetova H, Ledvinova J, Maas S: Subclinical course of cholesteryl ester storage disease in an adult with hypercholesterolemia, accelerated atherosclerosis, and liver cancer. J Hepatol 2000, 32:528-534

33. Jiang C, Ting AT, Seed B: PPAR-gamma agonists inhibit production of monocyte inflammatory cytokines. Nature 1998, 391:82-86

34. Ricote M, Li AC, Willson TM, Kelly CJ, Glass CK: The peroxisome proliferator-activated receptor-gamma is a negative regulator of macrophage activation. Nature 1998, 391:79-82

35. Wang AC, Dai X, Luu B, Conrad DJ: Peroxisome proliferatoractivated receptor-gamma regulates airway epithelial cell activation. Am J Respir Cell Mol Biol 2001, 24:688-693

36. Lian X, Yan C, Qin Y, Knox L, Li T, Du H: Neutral lipids and peroxisome proliferator-activated receptor-\{gamma $\}$ control pulmonary gene expression and inflammation-triggered pathogenesis in lysosomal acid lipase knockout mice. Am J Pathol 2005, 167:813-821

37. Yan C, Ding X, Dasgupta N, Wu L, Du H: Gene profile of myeloidderived suppressive cells from the bone marrow of lysosomal acid lipase knock-out mice. PLoS One 2012, 7:e30701

38. Korolchuk VI, Saiki S, Lichtenberg M, Siddiqi FH, Roberts EA, Imarisio S, Jahreiss L, Sarkar S, Futter M, Menzies FM, O'Kane CJ, Deretic V, Rubinsztein DC: Lysosomal positioning coordinates cellular nutrient responses. Nat Cell Biol 2011, 13:453-460

39. Zoncu R, Efeyan A, Sabatini DM: mTOR: from growth signal integration to cancer, diabetes and ageing. Nat Rev Mol Cell Biol 2011, $12: 21-35$ 